\title{
Female-female aggression: structure of interaction and outcome in loggerhead sea turtles
}

\author{
Gail Schofield ${ }^{1,2, *}$, Kostas A. Katselidis ${ }^{1,3}$, John D. Pantis ${ }^{4}$, Panayotis Dimopoulos ${ }^{1}$, \\ Graeme C. Hays ${ }^{2}$ \\ ${ }^{1}$ Department of Environmental \& Natural Resources Management, University of Ioannina, G. Seferi 2, 30100 Agrinio, Greece \\ ${ }^{2}$ Department of Biological Sciences, Institute of Environmental Sustainability, University of Wales Swansea, \\ Singleton Park, Swansea SA2 8PP, UK \\ ${ }^{3}$ National Marine Park of Zakynthos, 1 El. Venizelou Street, 29100 Zakynthos, Greece \\ ${ }^{4}$ Department of Ecology, School of Biology, UP Box 119, Aristotle University of Thessaloniki, 54006 Thessaloniki, Greece
}

\begin{abstract}
Aggressive behaviour between females of the same species is not widely documented, particularly in marine vertebrates. During a 3 yr in-water survey at the temperate loggerhead sea turtle Caretta caretta breeding area of Zakynthos, Greece, female-female interactions comprised $4 \%$ of all female loggerhead sighting events ( $n=60$ out of 1449 events). Male-female interactions comprised an additional $4 \%$ of sighting events, while $92 \%$ were of solitary females. The structure of interactions was analysed for 58 of these sighting events, each lasting an average of $3.4 \mathrm{~min}(\mathrm{SD} \pm 1)$ and comprising a total of $3.1 \mathrm{~h}$ observation time. We found that interactions involved ritualized escalation in behaviour from passive threat displays (e.g. head-tail circling) to aggressive combat (e.g. sparring). We suggest that circling individuals evaluate opponent size, sparring individuals test opponent strength, and that the positioning of the prehensile tail signals motivational intent to either escalate or abort. The presence of intruder females triggered a passive response in $100 \%$ of events involving basking and swimming turtles $(\mathrm{n}=19)$; although residents resting on the seabed only responded on $69 \%$ of occasions $(n=27)$, their response was almost 4 times more likely to escalate to one of aggression. Our results suggest that certain sites may be preferentially sought after and defended by sea turtles.
\end{abstract}

KEY WORDS: Caretta caretta - Sequential assessment · Evolutionary stable strategy · Territory · Marine $\cdot$ Vertebrate $\cdot$ Reptile Resale or republication not permitted without written consent of the publisher

\section{INTRODUCTION}

Although aggression between males is a widespread phenomenon, the same behaviour between females is less frequently documented (Liker \& Szekely 1997). Aggressive behaviour primarily arises to exclude intruders from defended areas in order to avoid competition for resources (Petrie 1984). Intra-specific aggression usually serves to establish hierarchy among individuals for access to resources. In the case of females, aggression is usually related to factors that affect their own and/or their offspring's survival: for instance food, mates, gestation sites, nest sites and sites to evade predators (Gowaty \& Wagner 1988, Liker \& Szekely 1997, Woodley \& Moore 1999). Such behav- iour requires an individual to invest in defence (e.g. to expend energy and/or time) so that some kind of benefit can be obtained (e.g. improved ranking or exclusive access to a limited resource). Because the relative importance of each defended resource can vary in space and time, it is often difficult to explain the origin of aggression. However, the degree of aggression is usually correlated with opponent capability and/or resource availability (Brown 1964).

Confrontations between 2 individuals are usually characterised by specific stereotypical behaviour that is divided into stages of escalating aggression (Ruby 1978) in which individuals evaluate and test the ability of the opponent (Parker 1974, Maynard Smith 1994). Contests are usually resolved through low cost dis- 
plays of physical attributes (Ruby 1978), and only escalate into costly aggressive (agonistic) interaction if neither competitor retreats (Enquist \& Leimar 1983). The outcome of escalated contests depends on a range of parameters such as competitive ability (resource holding power) and occupancy of a territory or hierarchical rank (prior residency effect). The residing individual is usually expected to win because, over time, the optimal sites/ranks are occupied by superior competitors (evolutionary stable strategies; Maynard Smith \& Price 1973, Parker 1974). However, a range of factors associated with individual fitness and/or resource value may also affect competitor motivation and hence contest outcome (pay-off asymmetries such as contest duration and previous encounters; Kotiaho et al. 1999, Cressman et al. 2004).

Although aggressive behaviour and contest escalation is widely documented for many vertebrates and invertebrates, direct observations of the aggressive behaviour of free-living animals in the marine environment is primarily limited to captive studies, usually of fish (Bisazza \& Pilastro 1997). Most research on large free-living marine animals relies on the attachment of electronic devices, such as data-loggers and satellite transmitters, to elucidate animal behaviour (e.g. of fish, seabirds, seals, whales, dolphins and sea turtles) related to diving and migratory activity. Although electronic devices have the capacity to record a range of animal movements, physiological processes and environmentally related parameters, at present they cannot - with the exception of camera systems - be used to infer intra- and inter-species interactions. Yet such interactions may be key to establishing how individuals utilise habitats and function within larger marine ecosystems.

Sea turtles are deep-diving migratory marine vertebrates; hence, remote technology has played an important role in understanding their aquatic activity (Hays

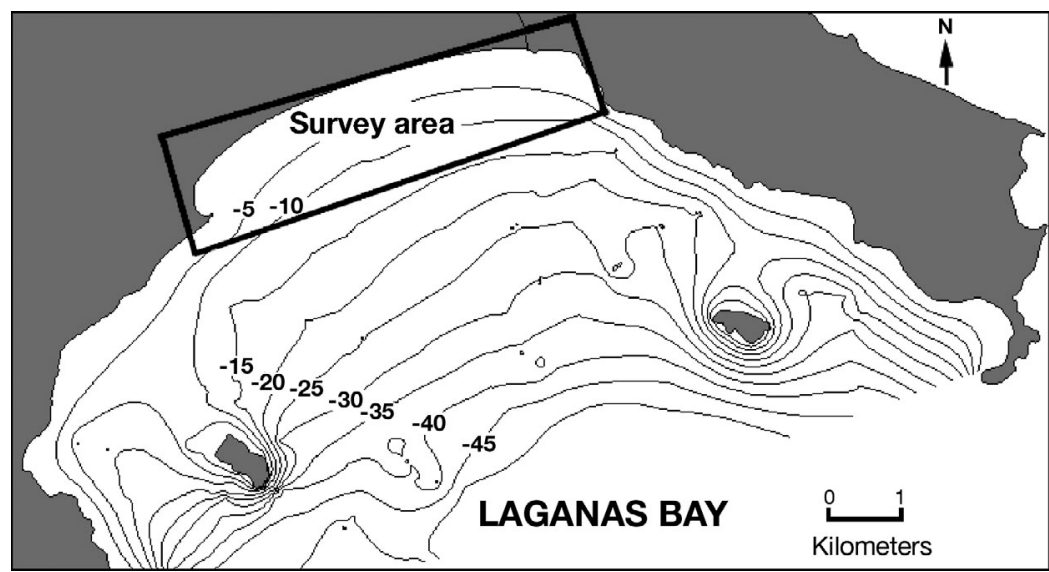

Fig. 1. Survey area $\left(37^{\circ} 66^{\prime}-37^{\circ} 73^{\prime} \mathrm{N}, 20^{\circ} 84^{\prime}-20^{\circ} 99^{\prime} \mathrm{E}\right)$ in Laganas Bay on the Ionian island of Zakynthos, Greece. Bathymetry contours (m) indicated et al. 2002a, Myers et al. 2006). However, without reliable comparative direct behavioural observations (Booth \& Peters 1972, Whittow \& Balazs 1982, Houghton et al. 2003) there is a risk of misinterpreting or even overlooking aspects of sea turtle biology (as shown by Houghton et al. 2002). For instance, telemetry studies have shown that sea turtles are solitary, even when individuals of a particular species share overlapping home ranges at foraging or breeding site aggregations (Hays et al. 2002b, Murphy-Hopkins et al. 2003). Nevertheless, there is anecdotal evidence of aggressive interactions between individuals when in close proximity to one another (Herbst \& Jacobson 2000, Limpus \& Limpus 2003).

Laganas Bay on the island of Zakynthos (Greece) is a major breeding area for loggerhead sea turtles Caretta caretta (Margaritoulis 2005). Several hundred turtles seasonally aggregate nearshore, making it relatively easy to acquire quantitative information on their aquatic behaviour through direct observation. As part of an ongoing in-water survey, we recorded repeated instances of female-female interactions. In the present study, we describe the stages of contest escalation from passive displays to aggressive combat. Based on existing theoretical game models of competition, we suggest how opponents communicate information on capability and motivation, and we discuss possible reasons for aggressive behaviour among female loggerhead sea turtles.

\section{MATERIALS AND METHODS}

Laganas Bay is about $12 \mathrm{~km}$ long by $8 \mathrm{~km}$ wide, and is situated on the Greek island of Zakynthos (study area: $\left.37^{\circ} 66^{\prime}-37^{\circ} 73^{\prime} \mathrm{N}, 20^{\circ} 84^{\prime}-20^{\circ} 99^{\prime} \mathrm{E}\right)$. Since 2003 , in-water surveys have been conducted there annually between April and July, thus encompassing the loggerhead sea turtle breeding season (courtship and inter-nesting periods). Surveys were organised to cover a range of daylight hours between 08:00 and 20:00 h. They lasted 2 to $6 \mathrm{~h}$ depending on the method used (e.g. boat, kayak or snorkelling) and weather conditions. Boat, kayak and snorkel surveys were concentrated along a $5.5 \mathrm{~km}$ stretch of nearshore area at sea depths of up to $10 \mathrm{~m}$, depths at which large numbers of female loggerhead sea turtles tend to aggregate during the breeding season (Fig. 1).

On sighting a sea turtle from the boat or kayak, the distance to the individual and the GPS location were recorded. The observer then entered the water at 
a distance of at least $5 \mathrm{~m}$ from the target animal(s) and approached until within underwater visual range. Surveys were only conducted when the underwater visual range (which varied according to sea state) exceeded $2 \mathrm{~m}$, in order to minimize disturbance of ongoing behaviour. On encountering the animal(s), photographs were taken, and biological, environmental and behaviour observations (ongoing behaviour and behavioural response to the presence of the underwater observer) were recorded. Written records were made of all behavioural observations. In events involving social interactions, the start and end times were recorded and the position in which the tail was held at the beginning and end of interactions was documented in writing. During 2005, video footage was collected to classify all observed solitary and social behaviour as well as inter-species interactions. Sex was estimated using previously documented tail-length dichotomies for mature adult male and female turtles (Casale et al. 2005).

We calculated mean and standard deviation for normally distributed metric data. We used non-parametric chi-square statistical analysis to assess the correlation between behavioural states and confrontation data (passive versus aggressive). We regarded results to be significantly different from $H_{0}$ when $\mathrm{p}<0.05$.

\section{RESULTS}

Female-female interactions comprised $4 \%$ of all female loggerhead sea turtle sighting events ( $\mathrm{n}=60$ out of 1449 events) during the $3 \mathrm{yr}$ survey. Malefemale interactions comprised an additional $4 \%$ of sighting events while $92 \%$ of sighting events were of solitary females. We recorded the structure of 60 contests each lasting an average of $3.4 \mathrm{~min}(\mathrm{SD} \pm 1$; range 1-6 min), comprising a total of $3.1 \mathrm{~h}$ of observations.

Prior to contests, the behaviour of the resident turtle was always solitary and consisted of resting on the seabed, $65 \%(\mathrm{n}=39)$; surface-basking, $13.5 \%(\mathrm{n}=8)$; swimming, $18.5 \%(\mathrm{n}=11)$; or fish cleaning symbiosis, $3 \%(n=2)$. Female interactions during fish cleaning symbiosis were excluded from the data set owing to the small sample size and because fish cleaning was only observed in the survey area during 1 season.

\section{Confrontation structure}

Turtles displayed a stereotyped sequence of escalating behaviour during contests. We divided contest escalation into 4 stages that could be concluded at any stage by the retreat of 1 opponent. The stages were (1) initial contact, stimulated by visual or tactile cues, (2) passive confrontation, comprising wide head-tail circling, with individuals maintaining a distance of $1.5 \mathrm{~m}$ from one another (3) aggressive confrontation, involving violent physical contact, (4) separation, with both turtles leaving or one fleeing and the other chasing. The confrontation structure and the outcomes of confrontations are presented in Fig. 2.

\section{Initial contact}

Initial contact occurred when intruders entered the visual range of residents. In all encounters of intruders with basking or swimming residents $(100 \%, \mathrm{n}=19)$ both turtles responded. However, while contact was made in the majority of encounters of intruders with residents resting on the seabed $(82 \%, \mathrm{n}=32)$, it was not always by both individuals.

Three scenarios were presented by resident turtles resting on the seabed ( $\mathrm{n}=39$ ) when an intruder entered their occupied space: (1) in 18\% (n = 7) of encounters the intruder passed by, either unnoticed or ignored, (2) in $54 \%(n=21)$ of encounters the intruder advanced on the resident turtle, obtaining visual contact and a defensive response by $91 \%(n=19)$ of resting site residents (Fig. 3) in which the anterior body and head were raised with mouth gaping (as observed by Limpus \& Limpus 2003), (3) in $28 \%$ ( $\mathrm{n}=11)$ of encounters the intruder advanced on the resident, obtaining no visual contact or defensive response, and proceeded to attack the resting turtle by nuzzling or biting the carapace (Fig. 4), thus stimulating a response in $73 \%(n=8)$ of interactions.

\section{Passive phase}

Once visual contact was made with the left or right eye (depending on which side the intruder entered visual range), it was not broken until separation. At this point, passive confrontation was initiated in the form of wide head-tail circling, with individuals maintaining a distance of $1.5 \mathrm{~m}$. All intruder interactions with basking and swimming turtles $(n=19)$ led to a passive response, whereas residents resting on the seabed responded on only $69 \%$ of occasions $(n=27)$.

The majority of confrontations that progressed to the passive phase were actually resolved in that phase, i.e. $88 \%(n=7)$ of surface-basking, $91 \%(n=10)$ of swimming confrontations $(89.5 \%$ combined) and $63 \%$ ( $\mathrm{n}=$ 17 ) of seabed resting site confrontations. A significantly higher proportion of confrontations with resting site residents developed into aggressive confrontation than did those with surface-basking/swimming residents $\left(\chi_{1}^{2}=4.92, \mathrm{p}<0.02 ; 37 \%[\mathrm{n}=10]\right.$ and $10.5 \%[\mathrm{n}=2]$ respectively). 


\section{Aggressive phase}

Aggressive confrontation was triggered when one turtle stopped circling to face the other head-on. A sequence of physically violent interactions was initiated, starting with sparring, in which the turtles snapped at each others' jaws (Fig. 5), with one or both turtles holding offensive 'horizontal' or defensive 'vertical' positions in the water column. This progressed to close circling in which the turtles snapped at the opponent's posterior carapace and/or flippers, followed by chasing and snapping at the neck and/or central cara-

\section{CONTACT BEHAVIOUR}

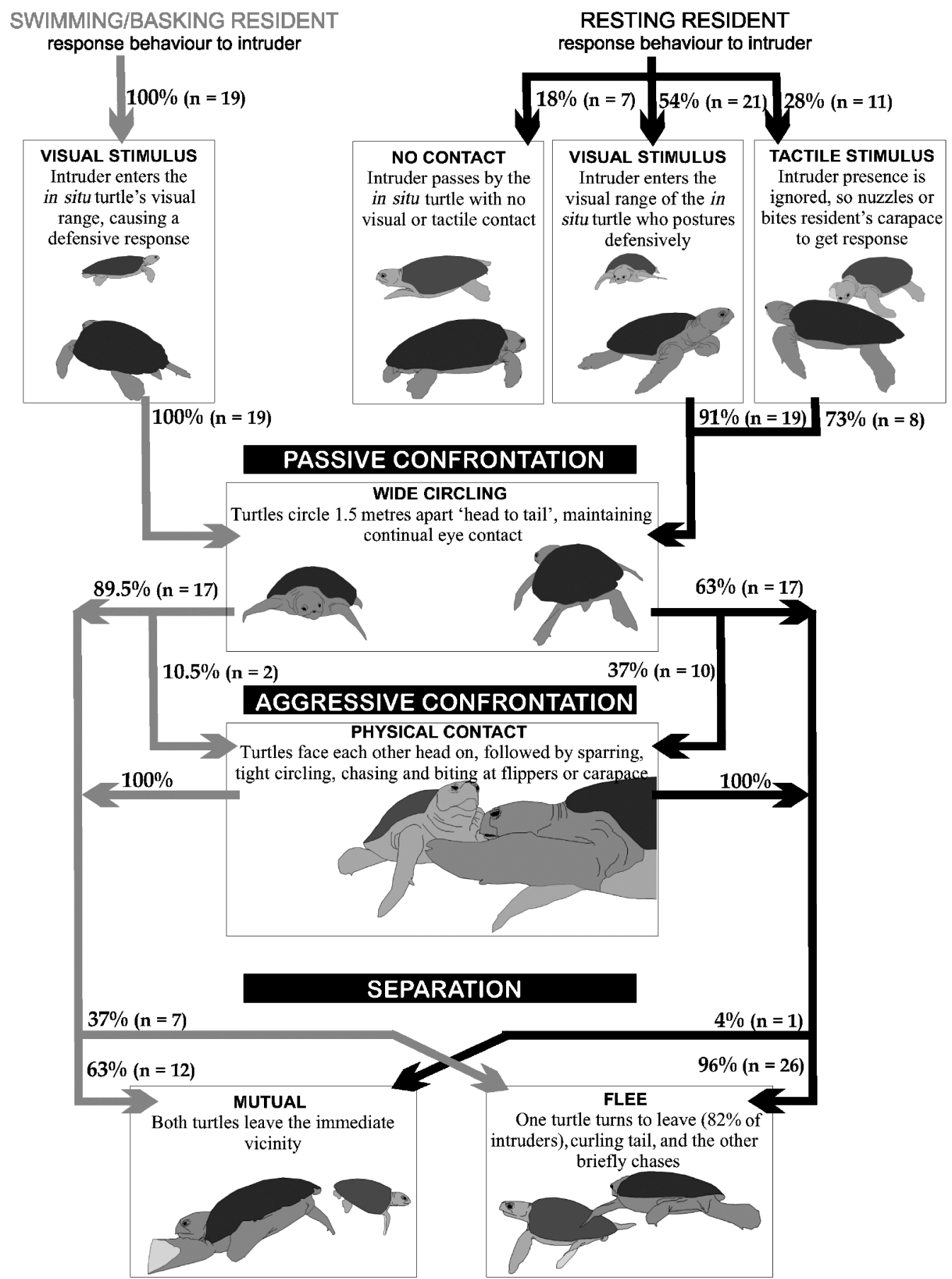

Fig. 2. Caretta caretta. Stages of female-female loggerhead competition; \% values on arrows indicate outcomes from different interactions 


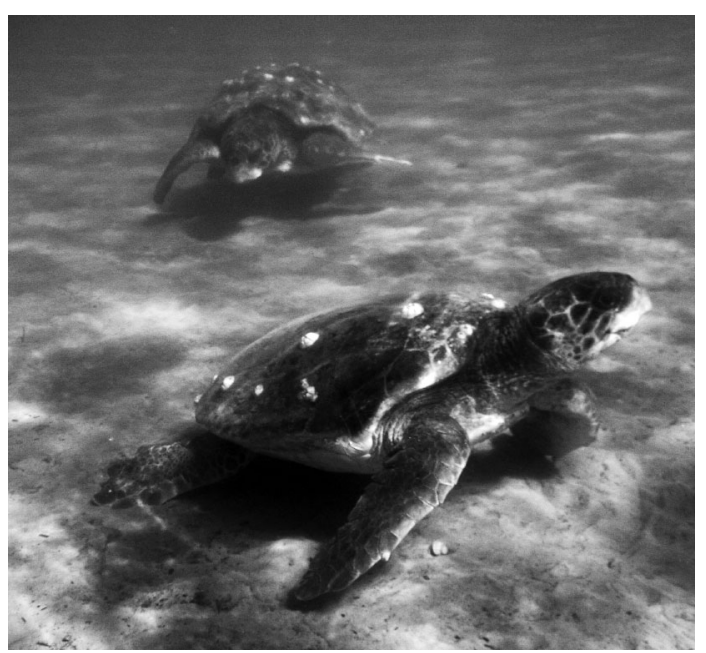

Fig. 3. Caretta caretta. Resident's visually provoked response to intruder

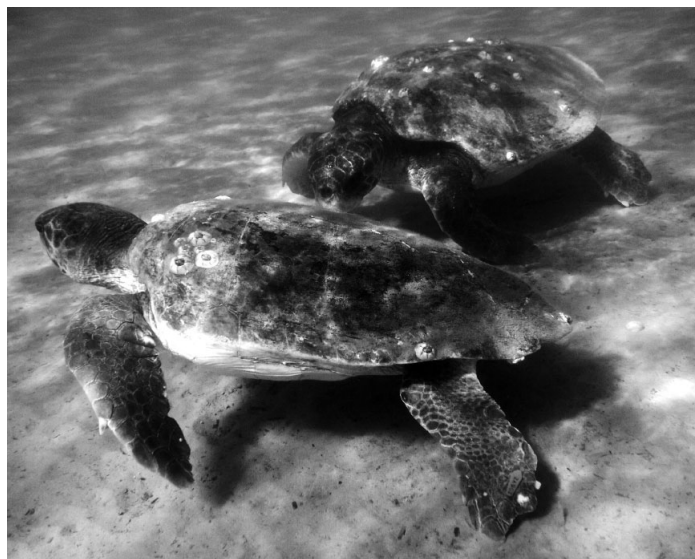

Fig. 4. Caretta caretta. Tactile stimulus by intruder to provoke resident response

pace. All aggressive confrontations involved sparring and $36 \%(n=4)$ progressed to close circling; of these $75 \%(n=3)$ progressed to chasing and biting before separation.

\section{Separation}

Separation was either mutual, with both turtles initially swimming away in generally opposite directions, or involved one opponent briefly chasing the other out of the immediate vicinity. Although the prehensile tail of adult male sea turtles has been documented to serve the primary function of curling under the female carapace for penile penetration (Miller et al. 2003), the present study noted that the prehensile tails of females used significantly often during confrontations $\left(\chi_{1}^{2}=\right.$ 3.89, $\mathrm{p}<0.04)$, possibly as a signal of the opponent's intention. In $70 \%(n=21)$ of passive and $80 \%(n=12)$

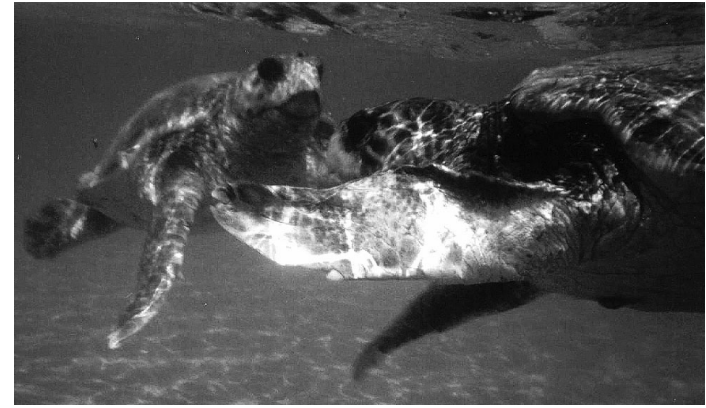

Fig. 5. Caretta caretta. Aggressive sparring between females

of aggressive interactions, the first turtle to depart visibly curled its tail immediately prior to separation.

Separation of intruders and resident surface-basking or swimming turtles was generally mutual (62.5\% [n = 5] and $63.5 \%$ [n = 7] respectively; $63 \%$ combined), with no significant difference observed between the frequency of capitulation (i.e. departure) of intruders and residents $\left(\chi_{1}^{2}=0.6, p<0.4\right)$. In confrontations with resting site residents, there was a $96 \%(n=26)$ probability that one of the opponents would flee rather than both depart mutually. Intruders were significantly more likely to depart first during passive and aggressive confrontations with resting site residents $\left(\chi_{1}^{2}=\right.$ $19.18, \mathrm{p}<0.001)$, with an intruder win rate of $15 \%(\mathrm{n}=$ 5 ) that was reduced by a further $5 \%$ during aggressive confrontations.

\section{DISCUSSION}

Our research illustrates that interactions between female loggerhead sea turtles are subject to escalation, the degree of which appears to differ with respect to behavioural state. Aggressive behaviour between females may arise (1) as a side-effect of elevated reproductive hormones (Woodley \& Moore 1999) or (2) as a side-effect of fending off male advances once receptivity has passed. However, resident females initially respond to males entering their visual range by holding a vertical 'refusal' pose (Booth \& Peters 1972), which is not observed until the aggressive phase of female-female interactions. Although heightened olfactory senses (Bartol \& Musick 2000) may enable residents to identify and respond to intruders accordingly, prior to their entrance into residents' visual range, this does not account for the incidence of aggressive behaviour also observed in foraging individuals and captive juveniles (Herbst \& Jacobson 2000, Limpus \& Limpus 2003).

Our observations indicate that interactions were more aggressive when they involved resting site loca- 
tions than when basking and swimming turtles were concerned, and that these locations were noticeably sought after by intruders. Marine environments are not homogeneous, and this behaviour indicates that turtles could be competing over a scarce high quality resource. These observations support the population 'interference' model derived from the 'Ideal Free Distribution' (Fretwell 1972, Sutherland \& Parker 1986) in that seabed resting sites may represent an optimal resource over which individuals compete, whereas surface-basking and swimming states occur at suboptimal sites subject to less competition.

In some breeding areas, female turtles have been observed to take refuge from energetically costly interactions with reproductively active patrolling males by occupying nearshore waters (Booth \& Peters 1972, Lee $\&$ Hays 2004). In this instance, space may be the limiting factor, whereby females resting in close proximity to one another would attract unwanted male attention. This may also account for the incidence of beach-basking behaviour of green turtles Chelonia mydas at Hawaii (Whittow \& Balazs 1982). Therefore, the size of the defended aquatic sites may correlate with the visual range of the resident, which is controlled by dynamic physical parameters such as light or sea clarity (Valdimarsson \& Metcalfe 2001).

Alternatively, detailed research has shown that, in gestating reptiles, environmental temperature affects the developmental rate and viability of offspring as well as adult growth and survival (e.g. lizards: Wapstra 2000, snakes: Ladyman et al. 2003). It is therefore possible that female turtles, particularly in temperate breeding areas, are responding to thermal cues in the environment by seeking out warmer water to accelerate gestation. Temperature regulation may also serve as an alternative explanation for Hawaiian green turtle beach-basking behaviour (Whittow \& Balazs 1982). This theory is further supported by comparative studies of sea turtle distribution in temperate and tropical breeding areas: in the former, where ambient sea temperatures are cooler, turtles form dense nearshore aggregations, whereas in the latter they remain more dispersed (e.g. Hays et al. 2002b).

In contests between female loggerhead sea turtles, we observed that established residents at seabed resting sites were more likely to win both passive (73\%) and escalated aggressive (68\%) contests, supporting established evolutionary ecology competition models (e.g. Parker 1974, Maynard Smith 1982, Enquist \& Leimar 1983). Competition escalation models predict that differences in opponent fighting ability should determine the outcome, usually favouring the stronger opponent. It is likely that initial resident status depends on time of arrival, whereas the length of residency depends on how rested the individuals are prior to each encounter combined with individual competitive ability.

Motivation to fight is influenced by many parameters related to individual fitness and resource value, and is subject to regular re-evaluation by each opponent, with respect to confrontation frequency, intensity and duration (e.g. Kotiaho et al. 1999, Cressman et al. 2004). We found that confrontations at surface-basking or swimming locations were more likely to mutually terminate at the passive stage; hence, resource value may also play an important role in determining fight duration and escalation (e.g. Kotiaho et al. 1999).

We suggest that a combination of size assessment and resource value could account for the 3 initial contact categories observed between occupants and intruders at resting sites. In cases with 'no contact', the intruder passes over an occupant with superior competitive ability or at a site of low resource value. In instances with a 'visual response', the intruder establishes visual contact, initiating a confrontation sequence with an equally matched resting site occupant. Finally, in interactions provoked by a 'tactile response', high resource value may motivate some intruders to provoke confrontations with opponents of superior competitive ability, although they have little chance of winning. Intruders that select the right opponent may have more to gain or less to lose than the established resident, resulting in the resident giving way to the intruder (Kotiaho et al. 1999), independent of the resident's holding power and strength.

When confronted with an opponent, competitors must acquire appropriate information about each other prior to initiating a fight. Such information is usually obtained through a set of passive threat displays (Ruby 1978). In sea turtles, passive head-tail circling behaviour may represent a 'cheap' way to determine opponent strength through size evaluation, while the position in which the prehensile tail is held may be an energetically inexpensive signal for motivational intent (with no correlation with animal strength). We suggest that tail position may be used to obtain information about the opponent's willingness to escalate or abort conflict at any stage of the combat sequence. An extended tail signals willingness to proceed, whereas tail curling at any part of conflict escalation indicates a competitor's decision to abort. Hence, when a contestant's decision to continue beyond passive head-tail circling is 'borderline', just a quick visual assessment of the opponent's tail position could determine intent.

Although cheap signals invite cheating (e.g. Parker 1974, Maynard Smith 1994), use of the tail to signal intent may be evolutionarily stable as long as both opponents benefit. While the costs of circling are low (in terms of energy and lost time), the expense of escalation to physical contact are high (risk of injury) and 
may keep cheating under control. Therefore, while sparring is not potentially dangerous, it may present an honest indicator of opponent strength and motivation (e.g. Kotiaho et al. 1999).

The way in which individuals of a species compete over resources allows researchers to objectively measure the importance of a particular environment, habitat or ecosystem to animals. Direct observation of free living marine animals is subject to a number of limitations; for instance, our study was limited by time of day, sea conditions and sea depth. Because of such limitations, use of remote technology is becoming increasingly common. However, without corroborated observational research, such technology only produces informed guesswork of animal behavioural activities. Advances in electronics are making underwater video cameras economically viable, giving the researcher the opportunity to obtain direct observational information within a wide range of marine settings (e.g. cameras may be hand-held or attached to the seabed, boat, remote-vehicle or study animal). By collecting direct baseline behavioural information, electronic devices could be subsequently used as a powerful tool to acquire specific information with respect to trends in marine animal social behaviour and habitat use. A useful goal for future studies would be to attempt to quantify the competitive abilities of fighting sea turtles and assess how their ability impacts the outcome of encounters. For example, it might be that competitive ability is related to body size or length of residency, as is the case in some other vertebrates (Downes \& Shine 1998, Gray et al. 2002). Our study can be considered a first step towards application of remote technology in order to specifically investigate possible causes of social interactions between sea turtles.

Acknowledgements. This research was permitted and financially supported by the National Marine Park of Zakynthos. We thank the many people who contributed to this research, especially A. Banks, K. Gounelis, V. Lianos, C. Sahlin and D. G. Schofield.

\section{LITERATURE CITED}

Bartol SM, Musick JA (2000) Sensory biology of sea turtles. In: Lutz PL, Musick JA, Wyneken J (eds) The biology of sea turtles, Vol II. CRC Press, Boca Raton, FL, p 79-99

Bisazzo A, Pilastro A (1997) Small mating advantage and reversed size dimorphism in poeciliid fishes. J Fish Biol 50:397-406

Booth J, Peters JA (1972) Behavioural studies on the green turtle (Chelonia mydas) in the sea. Anim Behav 20: 808-812

Brown JL (1964) The evolution of diversity in avian territorial systems. Wilson Bull 76:160-9

Casale P, Freggi D, Basso R, Argano R (2005) Size at male maturity, sexing methods and adult sex ratio in logger- head turtles (Caretta caretta) from Italian waters investigated through tail measurements. Herpetol J 15:145-148

Cressman R, Krivan V, Garay J (2004) Ideal free distributions, evolutionary games, and population dynamics in multiplespecies environments. Am Nat 164:473-489

Downes S, Shine R (1998) Heat, safety or solitude? Using habitat selection experiments to identify a lizard's priorities. Anim Behav 55:1387-1396

Enquist M, Leimar O (1983) Evolution of fighting behaviour: decision rules and assessment of relative strength. J Theor Biol 102:387-410

Fretwell SD (1972) Populations in a seasonal environment. Princeton University Press, Princeton, NJ

Gowaty PA, Wagner SJ (1988) Breeding season aggression of female and male eastern bluebirds (Sialia sialis) to models of potential conspecific and interspecific egg dumpers. Ethology 78:238-250

Gray SJ, Jensen SP, Hurst JL (2002) Effects of resource distribution on activity and territory defence in house mice, Mus domesticus. Anim Behav 63:531-539

Hays GC, Broderick AC, Glen F, Godley BJ, Houghton JDR, Metcalfe, JD (2002a) Water temperature and internesting intervals for loggerhead (Caretta caretta) and green (Chelonia mydas) sea turtles. J Therm Biol 27:429-432

Hays GC, Glen F, Broderick AC, Godley BJ, Metcalfe JD (2002b) Behavioural plasticity in a large marine herbivore: contrasting patterns of depth utilisation between two green turtle (Chelonia mydas) populations. Mar Biol 141:985-990

Herbst LH, Jacobson ER (2000) Practical approaches for studying sea turtle health and disease. In: Lutz PL, Musick JA, Wyneken J (eds) The biology of sea turtles, Vol II. CRC Press, Boca Raton, FL, p 385-440

Houghton JDR, Broderick AC, Godley BJ, Metcalfe JD, Hays GC (2002) Diving behaviour during the internesting interval for loggerhead turtles (Caretta caretta) nesting in Cyprus. Mar Ecol Prog Ser 227:63-70

Houghton JDR, Callow MJ, Hays GC (2003) Habitat utilisation of juvenile hawksbill turtles (Eretmochelys imbricata) in a shallow water coral reef habitat. J Nat Hist 37:1269-1280

Kotiaho JS, Alatalo RV, Mappes J, Parri S (1999) Honesty of agonistic signalling and effects of size and motivation asymmetry in contests. Acta Ethol 2:13-21

Ladyman M, Bonnet X, Lourdais O, Bradshaw D, Naulleau G (2003) Gestation, thermoregulation and metabolism in a viviparous snake, Vipera aspis: evidence for fecundityindependent costs. Physiol Biochem Zool 76:497-510

Lee PLM, Hays GC (2004) Polyandry in a marine turtle: females make the best of a bad job. Proc Natl Acad Sci USA 101:6530-6535

Liker A, Székely T (1997) Aggression among female lapwings, Vanellus vanellus. Anim Behav 54:797-802

Limpus CJ, Limpus DJ (2003) Biology of the loggerhead turtle in western South Pacific Ocean foraging areas. In: Bolten $A B$, Witherington BE (eds) Loggerhead sea turtles. Smithsonian Institution Press, Washington, DC, p 199-210

Margaritoulis D (2005) Nesting activity and reproductive output of loggerhead sea turtles, Caretta caretta, over 19 seasons (1984-2002) at Laganas Bay, Zakynthos, Greece: the largest rookery in the Mediterranean. Chel Conserv Biol 4:916-929

Maynard Smith J (1982) Evolution and the theory of games. Cambridge University Press, Cambridge

Maynard Smith J (1994) Must reliable signals always be costly? Anim Behav 47:1115-1120

Maynard Smith J, Price GR (1973) The logic of animal conflict. Nature 246:15-18

Miller JD, Limpus CJ, Godfrey MH (2003) Nest site selection, 
oviposition, eggs, development, hatching, and emergence of loggerhead turtles. In: Bolten AB, Witherington BE (eds) Loggerhead sea turtles. Smithsonian Institution, Washington, DC, p 125-143

Murphy-Hopkins SR, Owens DW, Murphy TM (2003) Ecology of immature loggerheads on foraging grounds and adults in internesting habitat in the eastern United States. In: Bolten $A B$, Witherington BE (eds) Loggerhead sea turtles. Smithsonian Institution Press, Washington, DC, p 79-63

Myers AE, Lovell P, Hays GC (2006) Tools for studying animal behaviour: validation of dive profiles relayed via the Argos satellite system. Anim Behav 71:989-993

Parker GA (1974) Assessment strategy and the evolution of fighting behaviour. J Theor Biol 47:223-243

Petrie M (1984) Territory size in the moorhen (Gallinula chloropus): an outcome of RHP asymmetry between neighbours. Anim Behav 32:861-870

Editorial responsibility: Rory Wilson (Contributing Editor), Swansea, UK
Ruby DE (1978) Seasonal changes in territorial behavior of the iguanid lizard Sceloporus jarrovi. Copeia 1978:430-438 Sutherland WJ, Parker GA (1986) Distribution of unequal competitors. In: Sibly RM, Smith RH (eds) Behavioural ecology: ecological consequences of adaptive behaviour. Blackwell Scientific Publications, Oxford

Valdimarsson SK, Metcalfe NB (2001) Is the level of aggression and dispersion in territorial fish dependent on light intensity? Anim Behav 61:1143-1149

Wapstra E (2000) Maternal basking opportunity affects juvenile phenotype in a viviparous lizard. Funct Ecol 14:345

Whittow GC, Balazs GH (1982) Basking behavior of the Hawaiian green turtle (Chelonia mydas). Pac Sci 36: 129-139

Woodley SK, Moore MC (1999) Female territorial aggression and steroid hormones in mountain spiny lizards. Anim Behav 57:1083-1089

Submitted: March 22, 2006; Accepted: July 28, 2006 Proofs received from author(s): February 22, 2007 